\title{
Favorable therapeutic response after anti-Mesothelin antibody-drug conjugate treatment requires high expression of Mesothelin in tumor cells
}

\author{
Lea Lazzerini ${ }^{1}$. Korinna Jöhrens ${ }^{2}$ · Jalid Sehouli ${ }^{1}$ Günter Cichon ${ }^{1}[$
}

Received: 5 November 2019 / Accepted: 31 July 2020 / Published online: 19 August 2020

(c) The Author(s) 2020

\begin{abstract}
Purpose The cell surface glycoprotein Mesothelin is overexpressed in ovarian, fallopian tube, endometrial, cervical and primary peritoneal cancer and, therefore, might become a particular interesting tumor target in gynecologic oncology. However, even in malignant tumors of the same entity the level of Mesothelin expression varies between individuals, hence it can be expected that the response to Mesothelin-targeting therapies will be variable as well. In this study we explored the therapeutic potency of a novel anti-Mesothelin antibody-drug conjugate (Anetumab ravtansine) as a function of Mesothelin expression in the targeted tumor cells.

Methods Anti-tumor activity studies were performed in human uterine xenograft tumor models that express Mesothelin at high, moderate or low levels. The antibody-drug conjugate (ADC) was applied in varying doses ranging from 2 to $15 \mathrm{mg} /$ $\mathrm{kg}$ at variable intervals in tumor bearing SCID/beige mice and the impact on tumor growth was monitored.

Results The therapeutic response to the anti-Mesothelin ADC correlated closely with the level of Mesothelin expression in tumor cells. Within the applied dose levels complete tumor regression was achieved only in tumors which expressed Mesothelin at particularly high levels (Hela cell tumors). The application of high anti-Mesothelin ADC doses less frequently was more efficious than giving lower doses at a higher frequency.

Conclusion The studies confirm the great therapeutic potential of Anetumab ravtansine. However, a favorable treatment outcome requires strong Mesothelin expression in tumor cells. Future clinical trials may benefit from a more rigorous selection of appropriate patients based on the level of Mesothelin expression in their tumor tissue. If, in addition, it is possible to better control side effects by introducing protective measures and by doing so to increase the maximum tolerated dose, Anetumab ravtansine has the potency to become a valuable therapeutic tool, especially in the field of gynecological oncology.
\end{abstract}

Keywords Mesothelin · Cancer · Anti-mesothelin drug conjugates $\cdot$ Anetumab ravtansine

\section{Introduction}

Mesothelin was first described by Chang and Pastan 1992 as a $40 \mathrm{kDa}$ membrane glycoprotein which is predominantly expressed in mesodermal tissue [1,2]. Mesothelin and its binding partner MUC16 (CA125) play a role in

Günter Cichon

guenter.cichon@charite.de

1 Department of Gynecology, Charité, Universitätsmedizin Berlin, Campus Benjamin Franklin, Hindenburgdamm 30, 12200 Berlin, Germany

2 Department of Pathology, Universitätsklinikum Carl Gustav Carus Dresden, Schubertstrasse 15, 01307 Dresden, Germany cell adhesion, whereas other physiologic functions are not known so far [3]. Mesothelin knock out mice show a normal phenotype indicating that this glycoprotein does not play an essential role in normal cellular physiology [4].

Mesothelin as a tumor target is particularly interesting in gynecology since the female inner genital organs are formed by the middle germ layer, the mesoderm. The upper part of the vagina, the uterus and the fallopian tubes develop from the mesodermal Müllerian duct (paramesonephric duct) [5]. Under physiological condition Mesothelin is expressed in these tissues, however the expression level increases substantially during malignant transformation [6]. Particularly high Mesothelin expression levels are found in the majority of pancreatic cancers, in ovarian cancer, in endometrium cancer and in cervical adenocarcinomas [7, 8]. Whether an 
increased Mesothelin expression provides a growth advantage for the tumor or has an impact on the prognosis is discussed controversially. Some reports describe high Mesothelin expression to be associated with a more aggressive behavior of the tumor and worse prognosis in breast, lung and gastric cancer [9-11] while others found no impact of Mesothelin overexpression on prognosis in gastric and breast cancer, or even an improved prognosis, respectively [12, 13].

The fact that membrane bound Mesothelin levels are increased in several human cancers and the protein is accessible from the extracellular space makes it a target for novel Mesothelin directed antibody-based therapies.

In the present study we explored the therapeutic effect of the antibody-drug conjugate Anetumab ravtansine. Anetumab ravtansine is an ADC in which a monoclonal antibody specific for human Mesothelin is bound to a highly toxic maytansinoid (DM4) [14]. Maytansoids are natural occurring agents which are isolated from plants and shrubs growing in Africa and other warm areas [15]. As a conjugate to an anti-Mesothelin antibody Anetumab ravtansine bounds to Mesothelin and becomes internalized by Mesothelinpositive tumor cells. Following internalization degrading enzymes release the cytotoxic maytansinoid DM4 which then acts as a microtubule destabilizer and induces cell cycle arrest and apoptosis [16].

Preclinical results and early clinical studies employing Anetumab ravtansine were very promising $[14,16]$. In a recent phase II trial the therapeutic potential of Anetumab ravtansine was explored as second line therapy in 248 mesothelioma patients who were no longer responsive to the standard therapy (Cisplatin/Pemetrexed). Unfortunately, in this trial the progression free survival of treated patients was not improved by the treatment compared to patients who received the standard therapy with Vinorelbine only [17]. Despite this drawback Mesothelin holds a potential as a novel target in oncology but it might be neccessary to revise the application regime, perform a stronger selection of patients suitable for treatment and improve associated measures which help to better control side effects and which might allow to increase the applied dose.

To explore the therapeutic potency and to optimize application regimes we performed dose-efficiency studies in three uterus derived human tumor models which express Mesothelin at variable levels.

\section{Material and methods}

\section{Generation of xenotransplant tumors in Scid beige mice}

\section{Animal experiments}

Animal experiments were approved by the state office for health and social affairs Berlin (Landesamt für Gesundheit und Soziales (Berlin); reference number G 0262/10. SCID/beige mice were purchased from Charles River laboratories (Sulzfeld, Germany). Hela and Caski cells were obtained from the DSMZ (Deutsche Sammlung für Mikrorganismen und Zellkulturen, Braunschweig, Germany) and the $\mathrm{Cx}-03$ cell line was established in our lab from a human uterine carcino sarcoma of the uterus [18]. Cells were cultured under standard conditions (DMEM, 10\% FCS, Pen/Strep; Thermo Fisher Scientific, Darmstadt, Germany). The anti-Mesothelin ADC Anetumab ravtansine was provided by Bayer AG (Berlin, Germany).

For generation of xenotransplant tumors $1 \times 10 \mathrm{e}-5$ trypsinized and washed vital tumor cells in $100 \mu \mathrm{LMEM}$ (without Pen/Strep and FBS) were injected subcutaneously into the back of the mice (27 gauge needle). Outgrowth of Hela and Cx-03 tumors took about 5-6 weeks and of Caski tumors about $7-8$ weeks.

The treatment with the anti-Mesothelin ADC was started when tumors had reached a size of 5-10 mm diameter. Animals in the treatment groups $(n=4-7)$ received $2 \mathrm{mg} / \mathrm{kg}, 5 \mathrm{mg} / \mathrm{kg}, 10 \mathrm{mg} / \mathrm{kg}$ or $15 \mathrm{mg} / \mathrm{kg}$ Anetumab ravtansine in $200 \mu$ linjection buffer (PBS) in different intervals (weekly, twice weekly or every 3 weeks) by i.p. injection. Animals in the control group received injection buffer only. Tumor size was monitored by caliper.

\section{Mesothelin staining of xenotransplant tumors}

Formalin fixed paraffin embedded tissue (FFPE) of Hela, Cx-03 and Caski tumors were stained with haematoxylin and eosin (HE) for histological tumor evaluation. To asses individual differences in expression patterns, five different xenograft tumors derived from each cell line were analyzed for Mesothelin expression. Mesothelin expression was determined on paraffin tissue sections by IHC staining using a Leica Bond ${ }^{\mathrm{TM}}$ polymer fully refine detection system. The employed anti-Mesothelin antibody was purchased from Thermo scientific (clone 5B2, 1: 100, Thermo Scientific MS-1320). A mesothelioma cell line was employed as positive control.

For determination of the Mesothelin expression level three representative high power fields from tumor samples 
were selected and the mean $\mathrm{H}$-score was calculated as the product of the relative proportion of Mesothelinpositive tumor cells (percent) and IHC staining intensity $(1+, 2+3+)$ as follows: $1 \times(\%$ cells $1+)+2 \times(\%$ cells $2+)+3 \times(\%$ cells $3+)$. The highest possible score is 300 .

\section{Results}

\section{Mesothelin expression levels in three uterine xenotransplant tumors}

To determine the average Mesothelin expression levels in the selected xenograft models, five xenograft tumors derived from each cell line were examined. In Caski cell xenotransplant tumors (Fig. 1a) Mesothelin expression was barely detectable (score 0-10), Cx-03 tumors (Fig. 1b) showed moderate expression levels (score 15-60) and Hela cell derived tumors (Fig. 1c) expressed Mesothelin to high levels (score 200-280).

\section{Therapeutic response to anti-Mesothelin ADC Anetumab ravtansine}

To evaluate the therapeutic potential of an anti-Mesothelin ADC dose-efficiency studies were started when tumors had reached a size of 5-10 $\mathrm{mm}$. In a first experiment animals received increasing doses from $2 \mathrm{mg} / \mathrm{kg}$ up $10 \mathrm{mg} / \mathrm{kg}$ twice weekly by intraperitoneal injection.

The results demonstrate a positive correlation between the level of Mesothelin expression in tumor cells and the sensitivity to the anti-Mesothelin ADC (Fig. 2). In Hela cell tumors a dose of $2 \mathrm{mg} / \mathrm{kg}$ applied twice weekly induced a mild retardation in growth speed but did not prevent tumor progression (Fig. 2b). Increasing the dose to $5 \mathrm{mg} / \mathrm{kg}$ twice weekly induced a sustained growth control in 4 of 8 animals and complete tumor remission in 2 of 8 animals (Fig. 2c). A further dose increase to $10 \mathrm{mg} /$ $\mathrm{kg}$ twice weekly led to complete tumor remission in 6 of 7 animals (Fig. 2d).

Compared to Hela cell derived xenograft tumors $\mathrm{Cx}-03$ tumors showed a reduced sensitivity against the MSLNADC. Applying a dose $2 \mathrm{mg} / \mathrm{kg}$ of the ADC twice weekly had no impact on growth speed compared to the control group (Fig. 2e, f). Increasing the dose to $5 \mathrm{mg} / \mathrm{kg}$ twice weekly induced a retardation in growth but did not prevent outgrowth of tumors (Fig. $2 \mathrm{~g}$ ). At a dose of $10 \mathrm{mg} / \mathrm{kg} 4$ of 7 animals showed a sustained growth control while in one animal tumor disappeared completely (Fig. 2h).

In Caski cell tumors ADC treatment remained mostly uneffective (Fig. 2i-h). Only in the highest dose group $(10 \mathrm{mg} / \mathrm{kg}$ twice weekly) a mild retardation in growth was noted which did not prevent tumor progression (Fig. 2i-k).

The first measurable response to the treatment usually occurred with a delay of 10-14 days. Even in the highest dose groups (10 mg ADC/kg) it took 3-4 applications to achieve a visible growth arrest (e.g. Fig. 2d).

To explore the impact of further dose increase $15 \mathrm{mg} /$ $\mathrm{kg}$ of the MSLN-ADC were applied at longer intervals (weekly and every 3 weeks) (Fig. 3). In this setting the therapeutic response occurred more rapidly and a complete tumor reduction was achieved in 6 of 6 Hela tumor bearing mice within 3 weeks (Fig. 3a). Giving the MSLN-ADC in longer intervals (once every 3 weeks) still provided a remission rate of $100 \%$ with some minor delay (Fig. 3b). In $\mathrm{Cx}-03$ the therapeutic response was less pronounced, but MSLN-ADC still induced complete tumor remission in 1 of 7, partial tumor remission in 2 of 7 and growth arrest in the other 4 animals (Fig. 3c). In the Caski model only a minor reduction in growth was noticed.

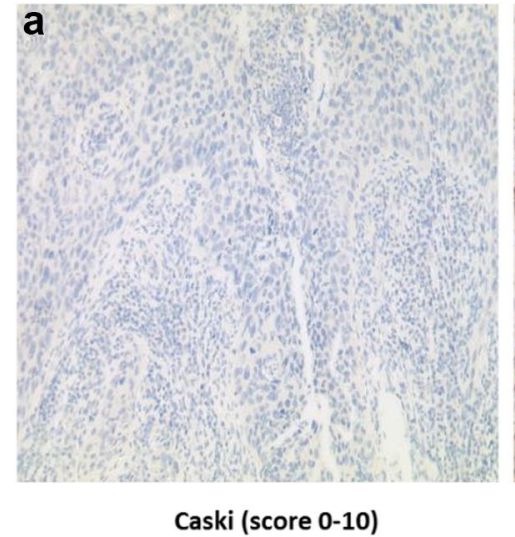

Caski (score 0-10)

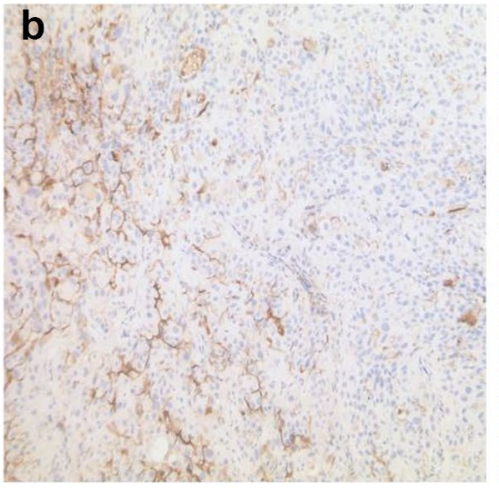

Cx-03 (score 15-60)

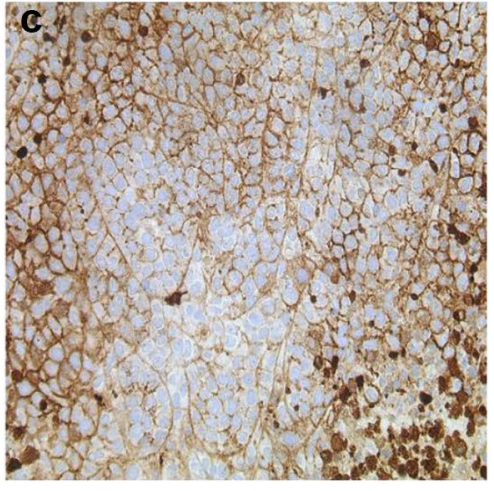

Hela (score 200-280)
Fig. 1 Mesothelin expression patterns in three different uterine carcinoma models. Caski (a) and HeLa (c) tumors are derived from cervical squamous cell carcinoma lines and $\mathrm{Cx}-03$ tumors (b) from a uterine carcinosarcoma. In Caski tumors Mesothelin expression is mostly absent while $\mathrm{Cx}-\mathrm{O} 3$ tumors show moderate and Hela tumors high Mesothelin expression levels 

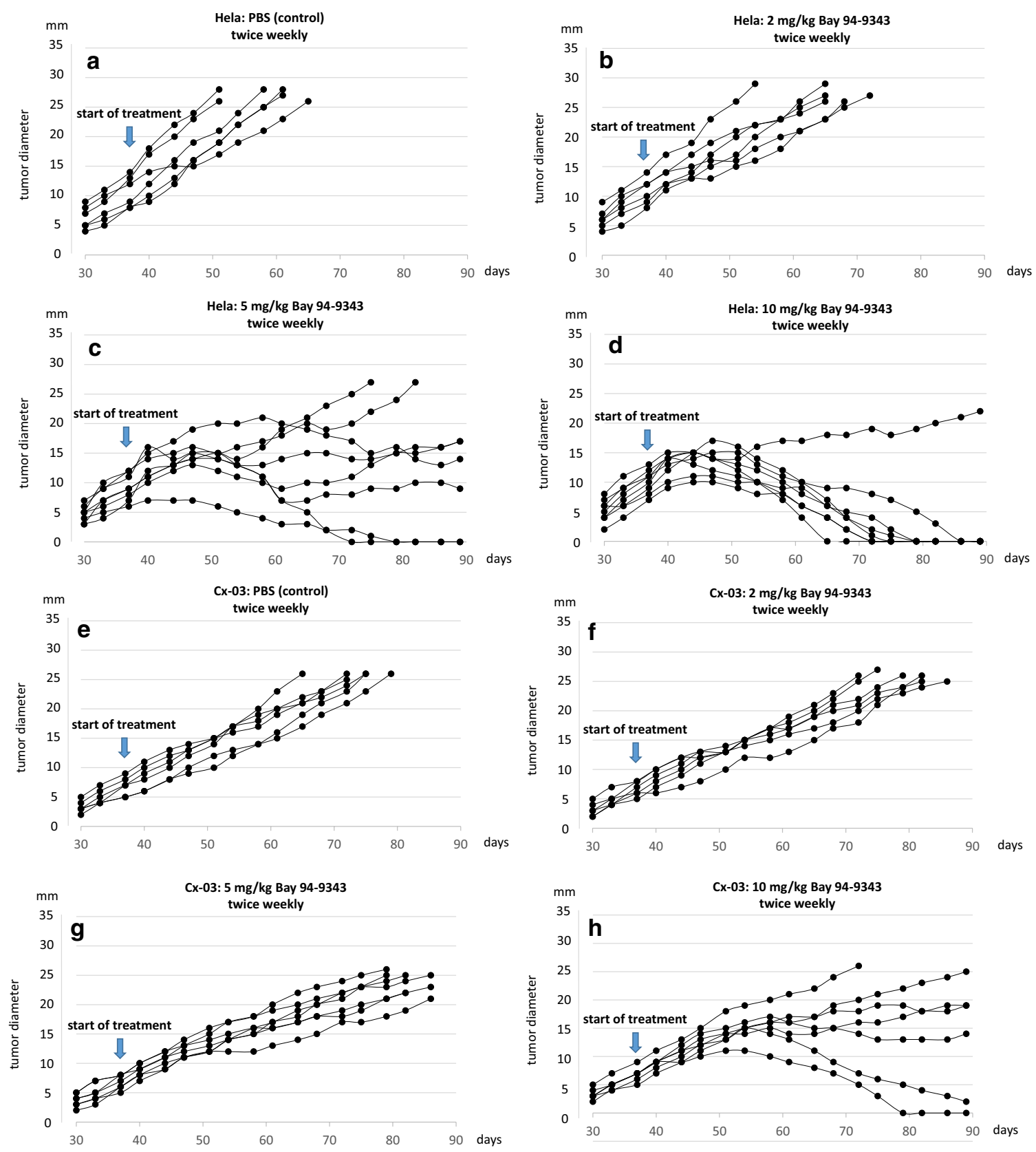

Fig. 2 Among the three explored uterine tumor models Hela cell derived tumors (a-d) show the highest sensitivity to the treatment with the anti-Mesothelin ADC. After applying $10 \mathrm{mg} / \mathrm{kg}$ twice weekly complete tumor remission is observed in 6 of 7 animals (d). Compared to Hela tumors $\mathrm{Cx}-03$ tumors $(\mathbf{e}-\mathbf{h})$ show a reduced

response, but a significant growth retardation is observed after applying a dose $10 \mathrm{mg} / \mathrm{kg}$ twice weekly and complete response in 1 animal (h). Caski cell tumor (i-k) are mostly unresponsive to the treatment and only a mild reduction in growth is observed at the highest ADC dose $(\mathbf{k})$

In the Hela group the repetitive MSLN-ADC application was stopped at day 90 after tumor cell inoculation and animals were further observed for additional 80 days. Tumor recurrence occured in only 1 of 6 animals of the $15 \mathrm{mg} / \mathrm{kg}$ weekly group (Fig. 4a) and 3 of 6 animals who received the ADC every 3 weeks (Fig. 4b).

\section{Discussion}

In the present study three human uterine tumor models which express Mesothelin at different levels were used to explore the efficacy of an anti-Mesothelin antibody drug 

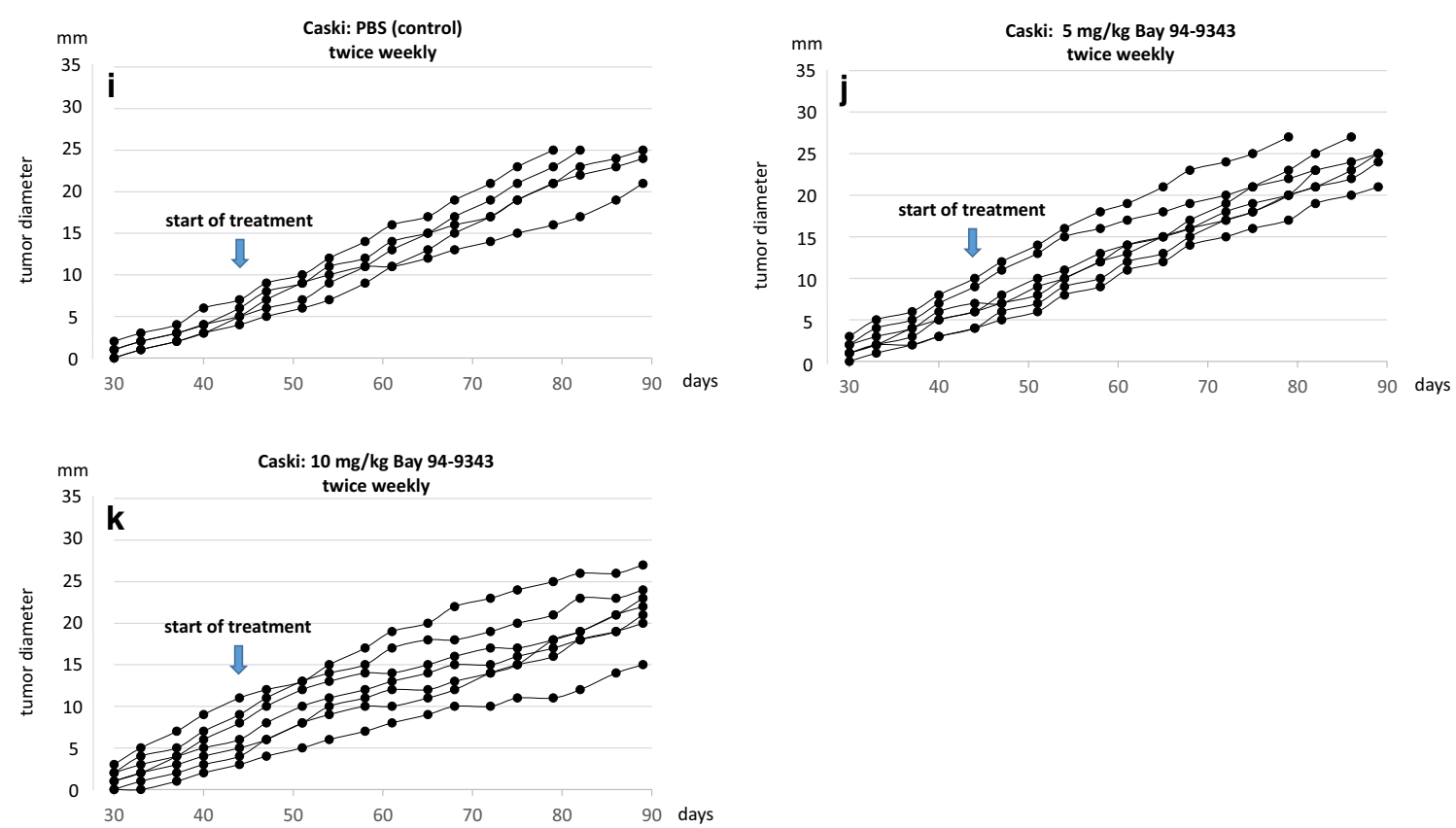

Fig. 2 (continued)
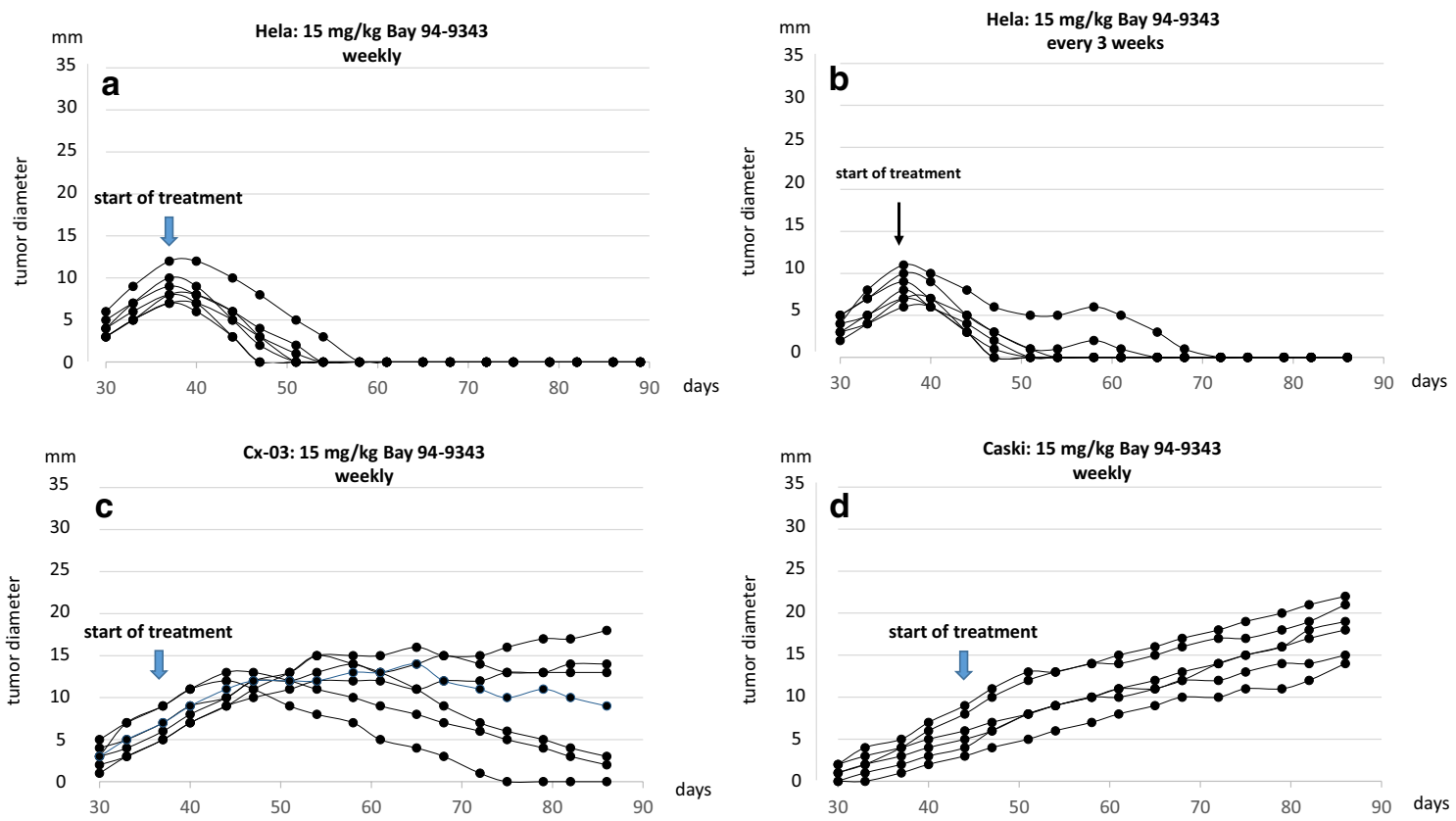

Fig. 3 Applying a dose of $15 \mathrm{mg} / \mathrm{kg}$ weekly (a) or every three weeks (b) leads to complete tumor regression in Hela cell tumors. In Cx-03 (c) and Caski cell tumors (d) no substantial difference was observed compared to the previous protocol (10 $\mathrm{mg} / \mathrm{kg}$ twice weekly)

conjugate (Anetumab ravtansine). Hela and Caski cells were originally derived from human squamous cell carcinoma of the cervix and $\mathrm{Cx}-03$ from a human uterine carcinosarcoma. Hela cell xenograft tumors express Mesothelin at high levels, low Mesothelin expression is found in $\mathrm{Cx}-03$ cell tumors and no Mesothelin expression is detected in Caski xenograft tumors. In this study MSLNADC application was initially performed in short intervals (twice weekly in doses ranging from 2 to $10 \mathrm{mg} / \mathrm{kg}$ ). The antibody drug conjugates were administered intraperitoneally, which ensures more reliable dosing, particularly in the case of repeated applications. After intraperitoneal 

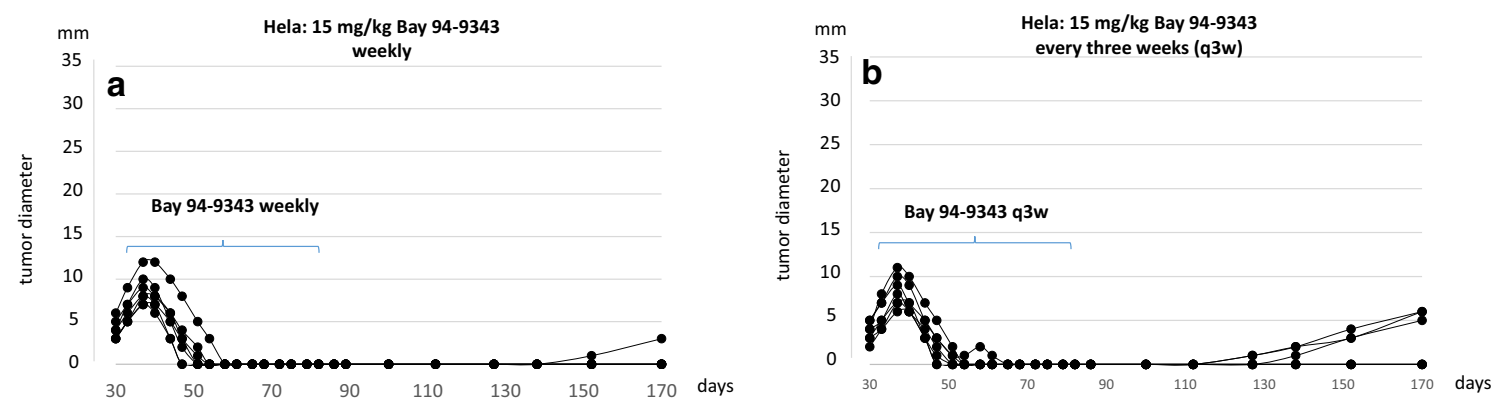

Fig. 470 days after termination of the treatment tumor recurrence occurred in 1 of 6 animals in the group which had received weekly ADC applications and three recurrences were noticed after applying the ADC every 3 weeks

administration, antibodies and antibody drug conjugate are well absorbed and lead to intratumoral drug concentrations close to that of intravenous administrations [19-21].

As expected, the therapeutic response was dependent on the applied dose and the expression level of Mesothelin in the xenograft tumors (Figs. 1, 2). In Hela derived tumors a dose of $10 \mathrm{mg} / \mathrm{kg}$ twice weekly induced complete tumor remission in more than $80 \%$ of animals, while in $\mathrm{Cx}-03$ tumors which expressed Mesothelin at 20-30\% compared to Hela tumors substantial tumor remission was noticed in 2 animals only and stable disease in the rest of the cohorte. The difference in the response rate of Hela and $\mathrm{Cx}-03$ tumors corresponded quite well to the level of their Mesothelin expression. Caski cell xenografts who did not express Mesothelin, remained mostly unresponsive to MSLN-ADC treatment.

Looking at the tumor growth curves it was recognized that a reduction of tumor mass did not occur immediately after applying the first dose of ADC but rather took 3-4 applications within at least $7-14$ days. When applying corresponding ADC doses to cell culture viability is decreasing within $24 \mathrm{~h}$ (data not shown). The different behavior of the tumor tissue in vivo may be due to deviating pharmacokinetic conditions and different tumor penetration patterns of ADC.

The half life of Anetumab Ravatasine in mice (in $20 \mathrm{mg} /$

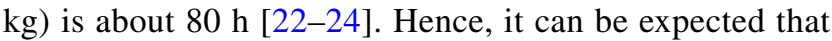
applying ADC twice weekly some accumulation might take place. We conclude from our experiments that a relevant reduction of tumor mass might only occur after reaching a sufficient intratumoral threshold concentration and that it is a high peak concentration rather than a high accumulative dose over time that provides a sufficient therapeutic response.

Efficient transvascular penetration and internalization of ADCs into tumor tissue is a prerequisite for a therapeutic effect. However, ADC distribution in tumor tissues is known to be nonuniform. It depends on the molecular size of the $\mathrm{ADC}$ and its affinity to the target antigen, the vascularization and capillary permeabilty of the tumor, intratumoral antigen distribution, intratumoral interstitial pressure and the grade of necrosis. John Weinstein and his colleagues provided evidence for another phenomenon which they called a 'binding site barrier' [25-27]. After initial intravenous application the first wave of the ADC penetrates the tumor tissues by trafficking through the intratumoral capillary walls and forms a dense layer of ADC-antigen complexes around the capillary which hinders the deep and homogenous penetration of subsequently inflowing ADCs. They have shown that the barrier could be in part overcome by a dose increase, however, as a consequence of this phenomenon serum levels and intratumoral ADC concentration might not behave in a linear mode. As long as the intratumoral ADC levels are not sufficient the therapeutic response will remain unsatisfactory. For this reason the application of high doses of ADC in longer intervals might provide a better outcome compared to the more frequent application of lower doses. This conclusion is in good agreement with the outcome of the second series of experiments. Applying a dose of $15 \mathrm{mg} / \mathrm{kg}$ weekly or every 3 weeks provides a better outcome than giving $10 \mathrm{mg} / \mathrm{kg}$ twice weekly (Fig. 3).

In humans physiological expression of Mesothelin is found in epithelial layers of the pleura, the peritoneum and the pericard, in salivary glands, in the bone marrow, the cornea and in intestinal tissues [28]. Utilizing Mesothelin as a tumor target is therefore afflicted with unwanted crossreactivity. Keratitis, neuropathy, fatigue, anorexia, asthenia, diarrhea and LFT increase are the most common drugrelated laboratory abnormalities which restrict the maximum tolerated dose in clinical trials to $6.5 \mathrm{mg} / \mathrm{kg}$ (q3w) [29].

In mouse models MSLN-ADC can be administered in significantly higher doses since Anetumab ravtansine does not crossreact with murine Mesothelin. Considering the different pharmacokinetics between humans and mice a dose of $6.5 \mathrm{mg} / \mathrm{kg}$ q3w (MTD in humans) corresponds to $15 \mathrm{mg} /$ $\mathrm{kg} \mathrm{q} 2 \mathrm{w}$ in mice [14].

In a second series of experiments it was shown that it a high peak level of the ADC rather than a high accumulative 
dose which provides and improved outcome (Fig. 3). This study confirms the potential of Anetumab ravtansine as an anti-tumor agent, however, the results suggest that aiming on a convincing clinical outcome a further dose increase and a restriction to patients displaying a strong intratumoral Mesothelin expression might be necessary. The screening and selection of patients suitable for Mesothelin-targeting therapies on the basis of their Mesothelin expression in tumor biopsies is easy to perform and daily routine in other tumor entities (e.g. HER2/neu in breast cancer). The major challenge seems to be the further increase of the applied dose in conjugation with a better control of side effects.

Mesothelin is a particular relevant and promising target especially in gynecologic oncology but it might be necessary to step back to suitable preclinical models to explore the benefit of antinflammatory and protective measures which help to control side effects and which might allow to increase the maximum tolerated doses.

Acknowledgements This study was funded by the Bundesministerium für Bildung und Forschung (BMBF) 03V0347 and the Bayer AG. The authors would like to thank Natalie Kuzaj and Andrea Wilke for the excellent technical support.

Author contributions LL: investigation, methodology; KJ: methodology; JS: supervision; GC: conceptualization, writing, review and editing.

Funding Open Access funding provided by Projekt DEAL.

\section{Compliance with ethical standards}

Conflict of interest Dr. Cichon received grant monies from Bayer AG. Prof. Sehouli receives funding for studies in ovarian cancer and serves on the Advisory Board as a consultant for Bayer. The other authors have no conflict of interest to declare.

Ethical approval The animal experiments were approved by the State Office for Health and Social Affairs (Berlin) in accordance with animal welfare regulations and valid ethical standards.

Open Access This article is licensed under a Creative Commons Attribution 4.0 International License, which permits use, sharing, adaptation, distribution and reproduction in any medium or format, as long as you give appropriate credit to the original author(s) and the source, provide a link to the Creative Commons licence, and indicate if changes were made. The images or other third party material in this article are included in the article's Creative Commons licence, unless indicated otherwise in a credit line to the material. If material is not included in the article's Creative Commons licence and your intended use is not permitted by statutory regulation or exceeds the permitted use, you will need to obtain permission directly from the copyright holder. To view a copy of this licence, visit http://creativecommons.org/licenses/by/4.0/.

\section{References}

1. Chang K, Pai LH, Batra JK, Pastan I, Willingham MC (1992) Characterization of the antigen (CAK1) recognized by monoclonal antibody K1 present on ovarian cancers and normal mesothelium. Cancer Res 52(1):181-186

2. Chang K, Pastan I (1996) Molecular cloning of mesothelin, a differentiation antigen present on mesothelium, mesotheliomas, and ovarian cancers. Proc Natl Acad Sci USA 93(1):136-140

3. Pastan I, Hassan R (2014) Discovery of mesothelin and exploiting it as a target for immunotherapy. Cancer Res 74(11):2907-2912

4. Bera TK, Pastan I (2000) Mesothelin is not required for normal mouse development or reproduction. Mol Cell Biol 20(8):2902-2906

5. Kurita T (2011) Normal and abnormal epithelial differentiation in the female reproductive tract. Differentiation 82(3):117-126

6. Hassan R, Ho M (2008) Mesothelin targeted cancer immunotherapy. Eur J Cancer 44(1):46-53

7. Hassan R, Thomas A, Alewine C, Le DT, Jaffee EM, Pastan I (2016) Mesothelin immunotherapy for cancer: ready for prime time? J Clin Oncol 34(34):4171-4179

8. Jöhrens K, Lazzerini L, Barinoff J, Sehouli J, Cichon G (2019) Mesothelin as a target for cervical cancer therapy. Arch Gynecol Obstet 299(1):211-216

9. Wang Y, Wang L, Li D, Wang HB, Chen QF (2012) Mesothelin promotes invasion and metastasis in breast cancer cells. J Int Med Res 40(6):2109-2116

10. Tozbikian G, Brogi E, Kadota K et al (2014) Mesothelin expression in triple negative breast carcinomas correlates significantly with basal-like phenotype, distant metastases and decreased survival. PLoS ONE 9(12):e114900. https://doi.org/10.1371/journ al.pone. 0114900

11. Kachala SS, Bograd AJ, Villena-Vargas J et al (2014) Mesothelin overexpression is a marker of tumor aggressiveness and is associated with reduced recurrence-free and overall survival in earlystage lung adenocarcinoma. Clin Cancer Res 20(4):1020-1028

12. Parinyanitikul N, Blumenschein GR, Wu Y et al (2013) Mesothelin expression and survival outcomes in triple receptor negative breast cancer. Clin Breast Cancer 13(5):378-384

13. Baba K, Ishigami S, Arigami $T$ et al (2012) Mesothelin expression correlates with prolonged patient survival in gastric cancer. J Surg Oncol 105(2):195-199

14. Quanz M, Hagemann UB, Zitzmann-Kolbe S et al (2018) Anetumab ravtansine inhibits tumor growth and shows additive effect in combination with targeted agents and chemotherapy in mesothelin-expressing human ovarian cancer models. Oncotarget 9(75):34103-34121

15. Iwasaki S (1998) Natural organic compounds that affect to microtubule functions. Yakugaku Zasshi 118(4):112-126

16. Golfier S, Kopitz C, Kahnert A et al (2014) Anetumab ravtansine: a novel mesothelin-targeting antibody-drug conjugate cures tumors with heterogeneous target expression favored by bystander effect. Mol Cancer Ther 13(6): 1537-1548

17. Kindler HL, Novello S, Fenell D et al (2017) Randomized phase II study of anetumab ravtansine or vinorelbine in patients with metastatic pleural mesothelioma. J Thorac Oncol 12(11):1746 (Suppl. 2, abstract OA 02.01)

18. Bucker R, Schaefer C, Gruber AD et al (2018) Establishment of a Mucin Secreting Cell Line Cx-03 from an Uterine Carcino Sarcoma. Pharm Res 36(1):7

19. Lin Y, Yuxi W, Yuqin Y et al (2014) Eradication of growth of HER2-positive ovarian cancer with trastuzumab-DM1, an antibody-cytotoxic drug conjugate in mouse xenograft model. Int $\mathbf{J}$ Gynecol Cancer 24(7):1158-1164 
20. Griffin TW, Collins J, Bokhari F et al (1990) Intraperitoneal immunconjugates. Cancer Res 50(3):1031-1038

21. Tibben JG, Massuger LF, Boermann OC, Claessens RA, Corstens FH (1994) Effect of route of administration on the biodistribution of radioiodinated OV-TL3 F (ab')2 in experimental ovarian cancer. Eur J Nucl Med 21(11):1183-1190

22. Kamath AV, Iver S (2015) Preclinical pharmacokinetic considerations for the development of antibody drug conjugates. Pharm Res 32(11):3470-3479

23. Sun X, Widdison W, Mayo M et al (2011) Design of antibodymaytansinoid conjugates allows for efficient detoxification via liver metabolism. Bioconjug Chem 22(4):728-735

24. Erickson HK, Park PU, Widdison WC et al (2006) Antibodymaytansinoid conjugates are activated in targeted cancer cells by lysosomal degradation and linker-dependent intracellular processing. Cancer Res 66(8):4426-4433

25. Saga T, Neumann RD, Heya T, Sato J, Kinuya S, Le N, Paik $\mathrm{CH}$, Weinstein JN (1995) Targeting cancer micrometastases with monoclonal antibodies: a binding-site barrier. Proc Natl Acad Sci USA 92(19):8999-9003
26. Weinstein JN, van Osdol W (2747s) Early intervention in cancer using monoclonal antibodies and other biological ligands: micropharmacology and the "binding site barrier". Cancer Res 52(9 Suppl):2747s-s2751

27. Juweid M, Neumann R, Paik C, Perez-Bacete MJ, Sato J, van Osdol W, Weinstein JN (1992) Micropharmacology of monoclonal antibodies in solid tumors: direct experimental evidence for a binding site barrier. Cancer Res 52(19):5144-5153

28. Uhlén M et al (2015) Tissue-based map of the human proteome. Science. https://doi.org/10.1126/science.1260419 (PubMed: 25613900)

29. Zhao XY, Subramanyam B, Sarapa N, Golfier S, Dinter H (2016) Novel antibody therapeutics targeting mesothelin in solid tumors. Clin Cancer Drugs 3(2):76-86

Publisher's Note Springer Nature remains neutral with regard to jurisdictional claims in published maps and institutional affiliations. 